\title{
Emergência de Klebsiella pneumoniae produtora de carbapenemase (KPC) em um hospital terciário
}

Primeira submissão em 11/10/11 Última submissão em 12/10/11 Aceito para publicação em 31/03/12 Publicado em 20/08/12

\section{Emergence of Klebsiella pneumoniae carbapenemase-producing (KPC) in a tertiary hospital}

Valéria Martins Soares

\section{unitermos}

Klebsiella pneumoniae carbapenemase

Resistência bacteriana a antimicrobianos

Carbapenêmicos

\section{resumo}

A resistência bacteriana é um problema frequente e importante no ambiente hospitalar. Oito cepas de Klebsiella pneumoniae produtoras de carbapenemase (KPC) foram isoladas de oito pacientes distintos, entre abril de 2009 e janeiro de 2011, no Hospital Júlia Kubitschek (HJK), localizado na cidade de Belo Horizonte, Brasil, seguindo os critérios definidos pelo Clinical and Laboratory Standards Institute (CLSI, 2009). Considerando o caráter emergente da KPC, torna-se importante seu rastreamento em isolados de enterobactérias com sensibilidade diminuída ao ertapenem.

\section{abstract}

Bacterial resistance is a frequent and major issue in nosocomial environment. In accordance with the standards proposed by the Clinical and Laboratory Standards Institute (CLSI, 2009), eight strains of Klebsiella pneumoniae (KPC) were isolated from eight distinct patients at Júlia Kubitschek Hospital (JKH), located in the city of Belo Horizonte, Brazil, between April 2009 and January 2011. As far as KPC emergence is concerned, its monitoring in Enterobacteriaceae isolates with decreased susceptibility to ertapenem has become highly important.

\section{key words}

Klebsiella pneumoniae carbapenemase

Antimicrobial resistance

Carbapenemase
A resistência bacteriana é um problema frequente e importante no ambiente hospitalar e várias bactérias apresentam habilidade de desenvolver mecanismos de resistência enzimáticos. Entre as enterobactérias, a produção de Klebsiella pneumoniae carbapenemase (KPC) é um mecanismo emergente, o que justifica sua vigilância constante ${ }^{(4)}$.

A KPC pode causar resistência a todos os agentes betalactâmicos, incluindo os carbapenêmicos, uma classe de antimicrobiano bastante usada para tratar infecções causadas por bactérias multirresistentes. $\mathrm{O}$ gene que codifica a enzima KPC foi identificado em plasmídeos, tendo grande potencial de disseminação. Os isolados geralmente apresentam resistência a outras classes de antimicrobianos que poderiam ser opções de tratamento ${ }^{(1)}$.

O primeiro relato de KPC ocorreu na Carolina do Norte, nos Estados Unidos, em 1996. Hoje é endêmica 
nesse país e segue com crescente número de casos nos últimos anos em todo o mundo. No Brasil, já foram reportados isolados de Klebsiella pneumoniae, Escherichia coli e Serratia marcescens carreando o gene blaKPC, ficando evidente a emergência desse tipo de carbapenemase e sua disseminação entre espécies diferentes de enterobactérias em nosso país ${ }^{(2,5,8)}$.

A partir de 2009, o Clinical and Laboratory Standards Institute (CLSI) passou a recomendar a pesquisa da enzima KPC em isolados de enterobactérias com resistência a cefalosporinas da subclasse III e sensibilidade diminuída a carbapenens pela metodologia de disco-difusão (ertapenem 19-21 mm; meropenem 16-21 mm; imipenem: fraco preditor de carbapenemase). Nessa situação, a padronização estabelece a confirmação de carbapenemase por meio do teste de Hodge modificado(3).

Diante do exposto, o objetivo deste artigo foi relatar o isolamento de cepas de Klebsiella pneumoniae produtoras de KPC (KPC-KPN) no Hospital Júlia Kubitschek (HJK) e mostrar que a triagem e a confirmação desse mecanismo de resistência têm sido bem conduzidas nessa instituição.

Este trabalho foi aprovado pelo Comitê de Ética em Pesquisa da Fundação Hospitalar de Minas Gerais, parecer número 063/2011.

No setor de Microbiologia do laboratório do HJK, um hospital geral de abrangência regional, localizado na cidade de Belo Horizonte, Brasil, o antibiograma é realizado por meio da metodologia de disco-difusão, segundo a padronização anual do CLSI. Assim, todas as cepas que se enquadravam nos critérios de triagem para KPC (resistência a cefalosporinas da subclasse III e sensibilidade diminuída a carbapenens pela metodologia de disco-difusão: ertapenem 19-21 mm; meropenem 16-21 mm) foram submetidas ao teste de Hodge modificado. Os isolados que apresentaram resultados fenotípicos positivos nesse teste foram encaminhados ao Laboratório de Pesquisa em Infecção Hospitalar da Fundação Osvaldo Cruz (FIOCRUZ, Rio de Janeiro), onde se realizou o teste de reação em cadeia da polimerase (PCR) para o gene blaKPC. Fez-se uma análise retrospectiva nos prontuários médicos dos pacientes para pesquisar o local onde foram isoladas as cepas de KPC-KPN, tipo de amostra clínica, idade, exposição prévia a antimicrobianos, tempo de internação no HJK e/ou em outras instituições. Oito KPC-KPN foram isoladas de oito pacientes distintos, entre abril de 2009 e janeiro de 2011. A idade dos pacientes variou de 47 a 90 anos. A maioria dos indivíduos (62,5\%) esteve hospitalizada por, pelo menos, 30 dias no HJK antes do isolamento de KPC-KPN. As cefalosporinas (62,5\%) foram os antimicrobianos mais comumente usados antes do isolamento de KPC-KPN, seguida dos carbapenêmicos (50\%). Seis cepas de KPC-KPN foram isoladas de amostras de urina, uma de sangue e uma de líquido peritoneal. Quanto ao padrão de sensibilidade, das oito cepas produtoras de $\mathrm{KPC}$, quatro isolados (50\%) apresentaram resistência ao meropenem e ao imipenem; cinco $(62,5 \%)$, ao ertapenem; e três cepas $(37,5 \%)$ apresentaram sensibilidade intermediária a esse antimicrobiano. Todas as cepas foram sensiveis à gentamicina, sete foram resistentes ao ciprofloxacin $(87,5 \%)$ e cinco (62,5\%) foram sensíveis à amicacina. Apenas uma cepa apresentou sensibilidade às cefalosporinas de subclasse III. As oito cepas com teste de Hodge positivo foram confirmadas por testes moleculares, apresentando resultados positivos por meio de PCR para o gen blaKPC.

Segundo alguns autores, o ertapenem apresenta melhor sensibilidade (90\%-100\%) e especificidade (81-93\%) para a enzima em questão, seguido de meropenem, com 48\%94\% e $96 \%-100 \%$, respectivamente. O disco de imipenem apresenta menor sensibilidade (42\%-94\%) e especificidade (28\%-93\%), sendo o menos recomendado ${ }^{(4)}$. Neste estudo, confirmou-se o melhor desempenho do ertapenem, uma vez que os oito isolados mostraram sensibilidade diminuída a esse antimicrobiano, enquanto o meropenem e o imipenem apresentaram desempenho similar, com sensibilidade diminuída em apenas $50 \%$ dos isolados.

No presente estudo, todas as cepas suspeitas e que apresentaram teste de Hodge modificado positivo foram confirmadas com teste molecular, mostrando que esse teste fenotípico foi capaz de determinar que a sensibilidade reduzida aos carbapenens era mediada por uma carbapenemase, confirmando os dados do CLSI sobre a alta especificidade (>90\%) e sensibilidade (>90\%) do teste na detecção de atividade de carbapenamases do tipo KPC(3). Neste trabaIho, o teste de Hodge modificado associado aos pontos de corte utilizados no antibiograma por metodologia de disco-difusão foi capaz de detectar a presença da enzima nos isolados. Ambos são considerados técnicas manuais simples e exequíveis em qualquer laboratório de microbiologia.

Durante esse período, foram observadas cepas com sensibilidade diminuída ao ertapenem e com teste de Hodge modificado negativo, porém esses dados não foram avaliados. Alguns estudos mostram que a resistência a carbapenens no antibiograma de K. pneumoniae não prediz a presença da enzima KPC. Outros mecanismos de resistência podem estar envolvidos, como a presença de betalactamases de espectro ampliado (ESBL) associada 
a betalactamases de classe $\mathrm{C}(\mathrm{AmpC})$, gerando pequena hidrólise de carbapenens e, ainda, alteração nos canais de porina, que modificam a ação e a penetração dos fármacos ${ }^{(4,8)}$. Autores europeus mostraram que entre 171 amostras de K. pneumoniae resistentes ao ertapenem, apenas duas continham uma carbapenemase não KPC.(7)

A presença de carbapenemases denota um panorama crítico no tocante à antibioticoterapia, uma vez que as opções terapêuticas tornam-se limitadíssimas. Neste estudo, $100 \%$ das cepas produtoras de KPC foram sensíveis à gentamicina. Alguns autores(6) relatam a porcentagem de resistência de $7 \%$ para gentamicina entre cepas que apresentam KPC, bem como 4,5\% para colistina e 15\% para tigeciclina, porém a porcentagem de resistência para estas não foi avaliada.
Uma das limitações deste estudo foi não ter sido pesquisada a relação genética entre os isolados para verificar possível disseminação clonal entre os pacientes. Apesar deste trabalho descrever um pequeno número de pacientes heterogêneos em uma única instituição, o relato da emergência da enzima KPC no HJK é um dado importante e de muita relevância epidemiológica, pois a enzima ainda é pouco reportada no Brasil e a bibliografia nacional é escassa. Além disso, os resultados mostram que a triagem para KPC tem sido conduzida adequadamente no HJK, com emprego de cefalosporinas subclasse III e de carbapenens no antibiograma, com realização do teste de Hodge modificado diante da sensibilidade diminuída, que apresenta sensibilidade e especificidade para confirmação da enzima KPC.

\section{Referências}

1. ANDERSON, K. F. et al. Evaluation of methods to identify the Klebsiella pneumoniae carbapenemase in Enterobacteriaceae. J Clin Microbiol, v. 45, n. 8, p. 2723-5, 2007.

2. BEIRÃO, E. et al. Clinical and microbiological characterization of KPC-producing Klebsiella pneumoniae infections in Brazil. Braz J Infect Dis, v. 15, n. 1, p. 69-73, 2011.

3. CLSI. Clinical and laboratory standards institute. Performance standards for antimicrobial susceptibility testing; Table: M100- S19; 940 West Valley Road, Suite 1400 Wayne, PA 19087-1898 USA, 2009.

4. DIENSTMANN, R. et al. Avaliação fenotípica da enzima Klebsiella pneumoniae carbapenemase (KPC) em Enterobacteriaceae de ambiente hospitalar. J Bras Patol Med Lab, v. 46, n. 1, p. 23-7, 2010.
5. ENDIAMIANI, A. et al. Emergence of blaKPC-containing Klebsiella pneumoniae in a long-term acute care hospital: a new challenge to our heathcare system. J Antimicrob Chemother, v. 64, n. 5, p. 1102-10, 2009.

6. HUSSEIN, K. et al. Carbapenem resistance among Klebsiella pneumonia isolates: risk factors, molecular characteristics and susceptibility patterns. Infect Control Hosp Epidemiol, v. 30, n. 7, p. 666-71, 2009.

7. MCGETTIGAN, S. et al. Specificity of ertapenem susceptibility screening for detection of Klebsiella pneumoniae carbapenemase. J Clin Microbiol, v. 47, n. 3, p.785-6, 2009.

8. MEYER, G.; PICOLI, S. D. Fenótipos de betalactamases em Klebsiella pneumoniae de hospital de emergência de Porto Alegre. J Bras Patol Med Lab, v. 47, n. 1, p. 666-71, 2009. 